\title{
Lipogenesis in cancer progression (Review)
}

\author{
CATHERINE MOUNIER, LAMIA BOURAOUI and ERIC RASSART \\ Biomed-Biological Sciences Department, UQÀM, Montréal, PQ, Canada
}

Received December 17, 2013; Accepted February 10, 2014

DOI: 10.3892/ijo.2014.2441

\begin{abstract}
In normal tissues, energy-providing lipids come principally from circulating lipids. However, in growing tumors, energy supply is mainly provided by lipids coming from de novo synthesis. It is not surprising to see elevated expression of several lipogenic genes in tumors from different origins. The role of lipogenic genes in the establishment of the primary tumor has been clearly established. A large number of studies demonstrate a role of fatty acid synthase in the activation of cell cycle and inhibition of apoptosis in tumor cells. Other lipogenic genes such as the acetyl CoA carboxylase (ACC) and the stearoyl CoA desaturase 1 (SCD1) are highly expressed in primary tumors and also appear to play a role in their development. However, the role of lipogenesis in the metastatic process is less clear. In the present review, we aim to present the most recent evidences for the key role of lipogenic enzymes in the metastatic process and in epithelial to mesenchymal transition.
\end{abstract}

\section{Contents}

1. Introduction

2. Lipogenesis, tumor growth and apoptosis

3. The metastatic process

4. Implication of fatty acid synthase

5. Implication of stearoyl CoA desaturase 1

6. Implication of other lipogenic genes

7. Conclusions

\section{Introduction}

Solid tumors require high levels of energy for growth and membrane synthesis. Lipids provide this energy. In normal tissues lipids come from circulating lipids, while cancer cells

Correspondence to: Dr Catherine Mounier, Biological Sciences Department, BioMed-UQÀM, 141 President Kennedy, Montréal, PQ H3C 3P8, Canada

E-mail: mounier.catherine@uqam.ca

Key words: lipogenesis, metastasis, epithelial to mesenchymal transition, fatty acid synthase, stearoyl CoA desaturase 1 mainly use de novo synthesized lipids (1). As a result, the rate of lipogenesis is highly induced (2).

Lipogenesis occurs both in liver and adipose tissues resulting in the synthesis of de novo fatty acids from acetyl CoA synthesized by glycolysis (Fig. 1). Acetyl CoA is then carboxylated by ACC forming malonyl CoA. Malonyl CoA and acetyl CoA are further processed by fatty acid synthase (FAS) in palmitic acid, which is then transformed by Elvol6 into stearic acid (3). SCD1 catalyzes the formation of palmitoleoylCoA and oleoyl-CoA from palmitoyl-CoA and stearoyl-CoA, respectively (4), which are preferentially transformed in triglycerides for storage in adipose tissue or phospholipids for membrane formation (5).

Expressions of ACC, FAS and SCD1 are under the control of the transcription factors LXR and the sterol regulatory element-binding protein-1c (SREBP-1c) (3). The 5' AMP-activated protein kinase (AMPK) has been implicated in the control of hepatic lipogenesis (6) through inactivation of ACC (7) and SREBP-1c (6). ACC and FAS are overexpressed in numerous types of cancers $(2,8)$ while high levels of mono unsaturated fatty acids (MUFA) were found in tumors (9) as a result of increased SCD1 expression and activity. SREBP1 has also been implicated in tumor growth (10). Therefore, high rate of lipogenesis is probably associated with tumorogenesis.

High lipogenic activity was also associated with cancer progression and metastasis (11). As suggested, high SREBP1 expression may explain at least in part the increased expression of lipogenic genes associated with stratification of the malignancy. However, independently of SREBP1, the lipogenic enzymes expression correlates with the state of malignancy. The most recent findings on the role of lipogenesis in cancer progression and metastatic process are presented.

\section{Lipogenesis, tumor growth and apoptosis}

An elevated FAS expression induces progression of cancer cells into $S$ phase (12). In contrast, inhibition of FAS expression decreases tumor growth and it induces apoptosis of cancer cells $(8,13)$. Elevated ACC expression is observed in the early stage of breast cancer (14) and silencing its expression results in growth inhibition and apoptosis of cancer cells (15-17). High SCD1 expression is associated with cancer cell proliferation (18) and with a decrease in cell death (18-21). SREBP1c also plays a role in the transformation of normal cells (22).

Lipogenesis is induced in cancer cells by EGF through activation of the HER2/neu receptor (23) and the PI3-kinase/Akt pathway (24-26) targeting SREBP-1 $(24,27)$. 


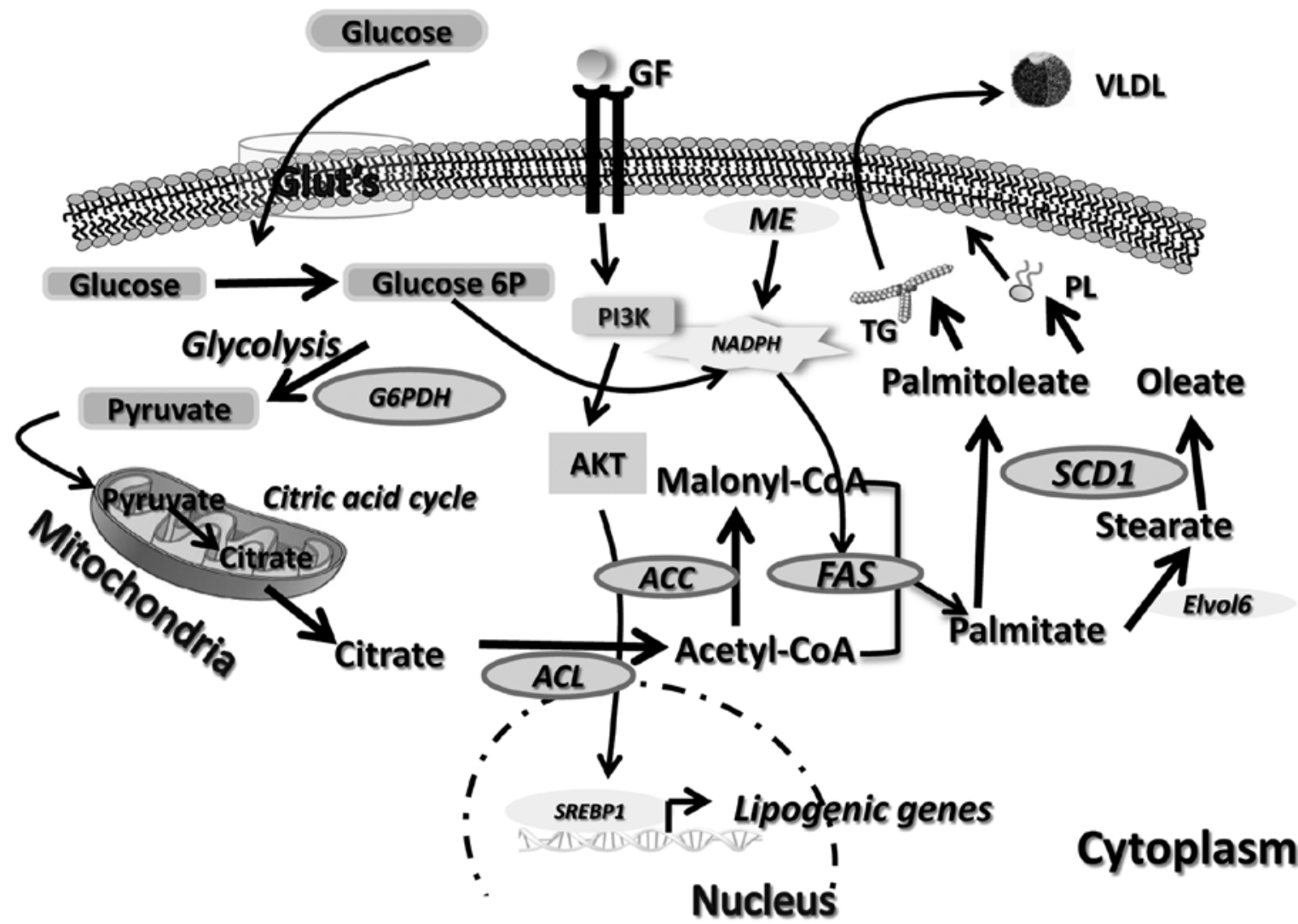

Figure 1. Lipogenesis. Upon glucose entry into the cells, pyruvate is formed through glycolysis. In the mitochondria, pyruvate is transformed to citrate. The ATP citrate lyase (ACL) forms acetyl CoA from citrate. Thereafter, the acetyl CoA carboxylase (ACC) transforms the acetyl CoA into malonyl CoA. Then, the fatty acid synthase (FAS) synthesizes the palmitate from acetyl CoA and malonyl CoA. For this reaction, FAS needs NADPH provided by malic enzyme (ME). The palmitate is then elongated through the action of the elongase Elovl6 forming the stearate. Palmitate and stearate are subsequently desaturated on $\Delta 9$ position by the stearoyl CoA desaturase (SCD1) forming palmitoleate and oleate respectively. These mono-unsaturated fatty acids are preferentially integrated into phospholipids (PL) for membrane synthesis or triglycerides (TG) for exportation in VLDL. Growth factors (GF) can increase lipogenesis through activation of a PI3K/AKT-dependent signaling pathway that phosphorylates and activates SREBP1, the main transcription factor regulating lipogenic genes expression.

As AMPK inhibits ACC by phosphorylation, its inactivation diminishes lipid supply and blocks cell cycle decreasing cell division and tumor growth (28). Therefore, lipogenesis probably provides energy supply to cancer cells stimulating cell division and survival leading to tumor growth.

\section{The metastatic process}

Metastasis is a complex multi-step process. Tumor cells need to escape from the primary tumor and to enter in the blood or in the lymphatic system. Most of the circulating cells undergo apoptosis (29) but some of them survive and invade new tissues (30). Epithelial to mesenchymal transition (EMT) has been associated with tumor progression and metastasis $(31,32)$. It dissolves tight junctions between epithelial cells, the extracellular matrix and the adherent basolateral junctions leading to a disorganized and mobile mesenchymal cell population (32).

One of the first events of EMT is the loss of E-cadherin, a transmembrane protein implicated in formation of the tight junctions (33). This is the result of increased expression of its transcriptional repressors $(34,35)$. In normal conditions, GSK $3 \beta$ phosphorylates E-cadherin transcriptional repressors targeting them to proteasome degradation thus allowing transcription of E-cadherin (36) (Fig. 2). In cancers, activation of TGF- $\beta$, Wnt, RTK and integrin pathways $(37,38)$ leads to inhibition of GSK3 $\beta$ (39). Consequently, E-cadherin transcriptional repressors are no longer phosphorylated nor degraded leading to inhibition of E-cadherin expression (40). Another consequence is the loss of $\beta$-catenin phosphorylation that cannot be targeted to the proteasome and accumulates in the cytosol. It further translocates to the nucleus where it activates the transcription of genes such as c-myc, an important cell cycle regulator $(41,42)$.

E-cadherin is also implicated in the actin cytoskeleton organization. Its direct binding to actin filament or to $\beta$-catenin maintains cell polarity and tissue architecture (43). In cancer cells, once the E-cadherin/ $\beta$-catenin complexes disappear, the actin network is disrupted modifying cell migration $(44,45)$. Nuclear $\beta$-catenin will also increase expression of mesenchymal proteins $(46,47)$. These molecular events will allow EMT inducing the migration and invasion of cancer cells and metastasis.

\section{Implication of fatty acid synthase}

Among the lipogenic enzymes implicated in the development of metastasis, FAS is certainly the most studied protein (Table I). Prognostic and survival of patients with cancer are mainly predicted by the presence of metastasis (48) and overexpression 

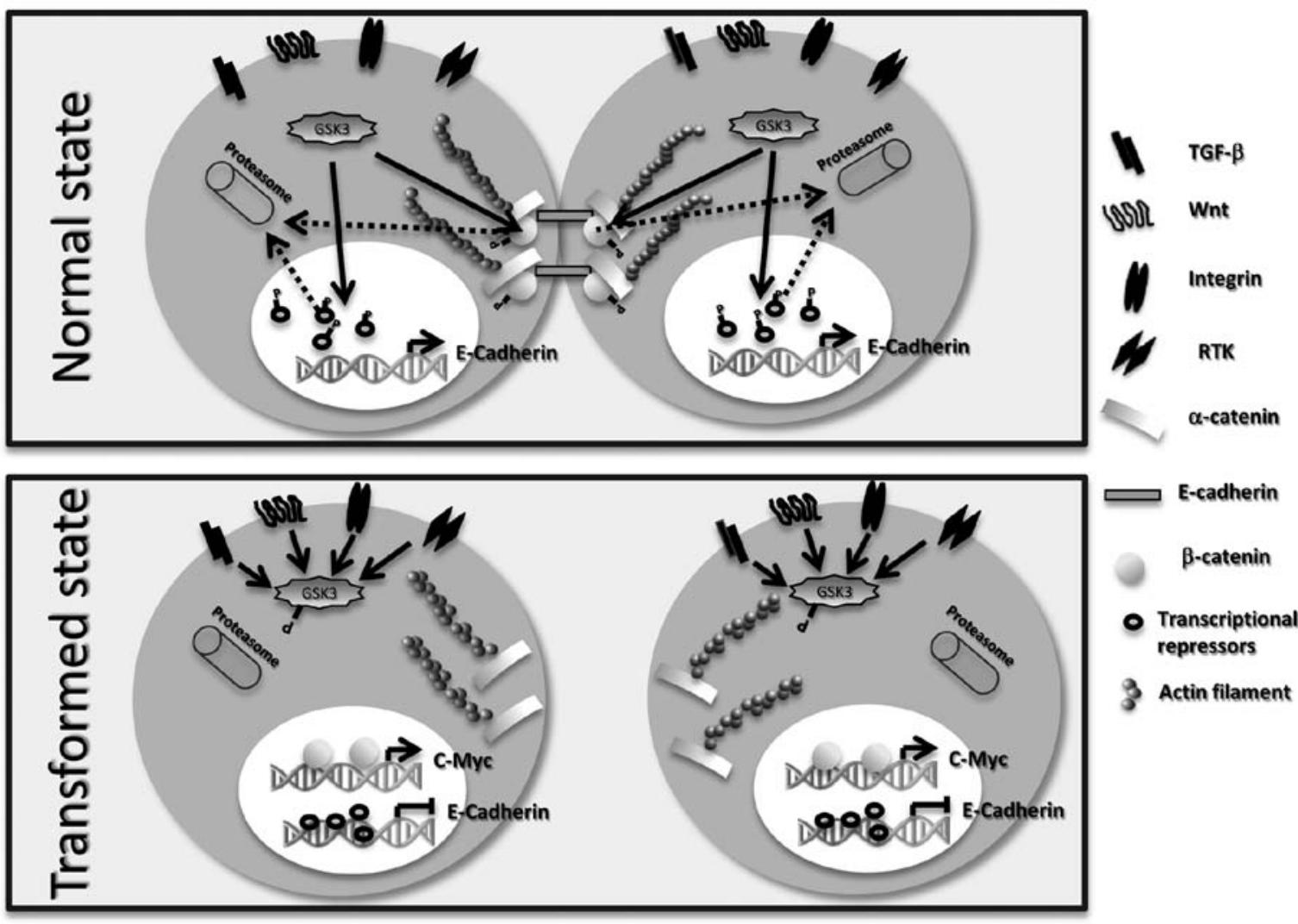

Figure 2. The epithelial to mesenchymal transition. In normal state, cells are associated together by a complex formed by E-cadherin, $\beta$-catenin and $\alpha$-catenin. This complex interacts with actin filament stabilizing cell interaction. In these conditions, GSK $3 \beta$ is not phosphorylated and can phosphorylate $\beta$-catenin and E-cadherin transcriptional repressors. Consequently, the phosphorylated proteins are targeted for proteosomal degradation. In a transformed state, upon activation of TGF- $\beta$, Wnt, integrin and RTK signaling pathways, GSK3 is phosphorylated and inactivated. Consequently, $\beta$-catenin and E-cadherin transcriptional repressors are not degraded. Therefore, $\beta$-catenin translocates to the nucleus where it activates c-Myc transcription while E-cadherin expression is inhibited. This leads to destabilisation of the cell-cell adhesion complex and disruption of the actin filament network.

of FAS has been associated with poor prognostics in several hormone-dependent cancers (49-52). The direct association between FAS expression and metastasis has also been observed in prostate cancers (53) and breast carcinomas (49).

In the transgenic adenocarcinoma of the mouse prostate (TRAMP) model which closely mirrors the progression of prostate cancer observed in human, FAS expression and activity are high compared to control littermates (54). Injection of immunodeficient mice with human prostate cancer cells overexpressing FAS and the androgen receptor (AR) leads to invasive adenocarcinomas (55). Androgens stimulate FAS expression in prostate cancers (55) by increasing the nuclear levels of SREBP (57). This is probably the result of increased SCAP expression that exports SREBP from the endoplasmic reticulum to the Golgi where it is activated by cleavage. As a consequence of androgen action on SREBP, expression of lipogenic genes is increased $(56,57)$. Downstream of the AR, the PI3K\Akt pathway has been implicated in FAS activation (58). In prostate cancer, the isopeptidase USP2a has been also implicated in the activation of FAS expression by inhibiting its proteosomal degradation (59).

In ovarian cancer cells, proteolysis degradation of FAS and focal adhesion kinase (FAK) cause a strong reduction of the vascular endothelial growth factor (VEGF)-mediated cell migration and invasion (60), in the same study, the isopeptidase USP2a was also shown to stabilize FAS. In breast cancer cells, the green tea extract EGCg causes accumulation of $\beta$-catenin in the cytosol and decreased expression of E-cadherin (61). EGCg appears to disturb cell adhesion by modifying FAS and the EGF receptor (EGFR) signaling pathway.

FAS has also been implicated in the transformation of breast cancer cells through an effect on the EGFR (HER2/neu isoform) expression (62). HER2/neu is a proto-oncogene associated with the development of metastasis in breast cancer (63). In HER2-positive cells, elevated FAS expression stabilizes the lipid rafts and consequently, HER2/neu expression is increased activating downstream signaling pathways (64). EGF also increases FAS transcription establishing a positive feedback loop between FAS and EGF (65-67).

FAS expression is stimulated by estrogen in both endometrial and breast cancer cells (51). However, this increase is probably associated with the establishment of the primary tumor as the presence of estrogen and progesterone receptors in tumors provide better prognostic for the patients than those expressing HER2/neu $(63,68)$.

Correlative associations between FAS expression and poor prognosis for patients were also observed in non-hormonedependent cancers (69-71) as well as with metastasis (72).

In metastatic renal cancer, FAS expression is strongly induced compared to non-transformed tumors (73). In human pancreatic cells, invasiveness was abolished by $\mathrm{C} 75$, a synthetic FAS inhibitor possibly through downregulation of 
Table I. Evidence for a role of fatty acid synthase in the development of metastasis in various types of cancer. These studies were performed in patients, in mice and transformed cancer cell lines.

\begin{tabular}{|c|c|c|c|c|}
\hline Role & Type of cancer & System & Implicated mechanisms & Refs. \\
\hline \multirow[t]{19}{*}{$\begin{array}{l}\text { Synthesis of } \\
\text { palmitate }\end{array}$} & $\begin{array}{c}\text { Ovarian } \\
\text { neoplasms }\end{array}$ & $\begin{array}{c}\text { Patients } \\
\text { A2780 and SKOV3 cells }\end{array}$ & $\begin{array}{l}\text { Oestrogen } \\
\text { Akt-USP2a }\end{array}$ & $\begin{array}{c}(52) \\
(25,60)\end{array}$ \\
\hline & $\begin{array}{c}\text { Breast } \\
\text { carcinomas }\end{array}$ & $\begin{array}{c}\text { Patients } \\
\text { MDA-MB-231, } \\
\text { MCF-10A, } \\
\text { BT474, and } \\
\text { SKBr3 cells }\end{array}$ & $\begin{array}{c}\text { EGF-oestrogen } \\
\text { HER2/neu }\end{array}$ & $\begin{array}{c}(23,48,49,51) \\
(23)\end{array}$ \\
\hline & & MCF7 cells & HER2/neu & $(62)$ \\
\hline & & SKRB3 cells & $\begin{array}{c}\text { Lipid rafts } \\
\text { PI3K/Akt and ERK1/2 }\end{array}$ & (64) \\
\hline & $\begin{array}{l}\text { Endometrial } \\
\text { carcinomas }\end{array}$ & Patients & Oestrogen & (51) \\
\hline & Prostate cancers & Patients & Androgen & $(50)$ \\
\hline & & Mouse TRAMP & Androgen & $(53,54)$ \\
\hline & & iPrECs cells & Androgen & $(55)$ \\
\hline & & $\mathrm{LNCaP} /$ & Androgen & \\
\hline & & MDA-PCa-2a cells & SREBP1/SCAP & (57) \\
\hline & & & PI3K/Akt pathway & (58) \\
\hline & & & USP2a & (59) \\
\hline & Renal cancers & Patients & & (73) \\
\hline & & $\begin{array}{l}\text { Caki- } 1 \text { cells } \\
\text { Renca cells }\end{array}$ & HER2/neu-STAT3 & (13) \\
\hline & $\begin{array}{l}\text { Head and neck } \\
\text { neoplasms }\end{array}$ & Patients & EGFR & $(71)$ \\
\hline & Lung carcinomas & Patients & & (74) \\
\hline & Colon cancers & $\begin{array}{l}\text { Mice xenograph } \\
\text { models }\end{array}$ & MET-AKT-FAK & $(76,77)$ \\
\hline & Melanomas & $\begin{array}{l}\text { Melanoma cell } \\
\text { line B16-F10 }\end{array}$ & & (75) \\
\hline & Retinoblastomas & Patients & & (69) \\
\hline
\end{tabular}

HER2/neu and/or STAT3 phosphorylation (72). In a mouse model of spontaneous melanoma metastasis, direct IP injection of Orlistat, a natural FAS inhibitor, inhibits metastasis in lymph nodes by more than $50 \%$ (75). In xenograft models of advanced colon cancer, inhibition of FAS decreased hepatic metastasis $(76,77)$ implicating AKT downstream of FAS. Inhibition of FAS also attenuates the activation of the MET receptor and FAK, two proteins implicated in adhesion, migration and invasion of cancer cells (60).

The above studies point to a key role of FAS in cancer progression, probably through modulation of lipid raft formation leading to activation of EGFR, HER2/neu and MET. Consequently, downstream signaling pathways are activated increasing nuclear localization of SREBP1c activating FAS and other lipogenic genes describing a positive feedback loop.

\section{Implication of stearoyl CoA desaturase 1}

An increased content of MUFAs has been observed in transformed cells suggesting a role for SCD1 in tumorigen- esis (9). The fatty acid profile and particularly the balance between saturated fatty acids (SFA) and MUFA can be used as predictor for breast cancer (78-80). It was recently demonstrated that silencing of SCD1 in breast cancer cells does not affect cell viability but inhibits cell cycle progression (81). In these conditions, expressions of key proteins involved in cell cycle progression are decreased. The degree of SCD1 inhibition appears directly correlated with inhibition of cancer cells proliferation (19) decreasing the amount of SFA (SCD1 substrates), the main inhibitors of ACC (82).

Others studies point for a role of SCD1 in cancer progression and metastasis (Table II). It was shown that MUFA content in cholesterol esters is associated with higher death rate in cancer patients (83) while elevated levels of oleic acid were observed in breast cancers with metastasis (84), suggesting an increased activity of SCD1. Low content of stearic acid (SCD1 substrate) in phosphatodylcholine were also measured in breast tumors associated with subsequent metastasis (9). In breast adipose tissues, no difference in MUFA content was observed between benign tumors and normal tissues, but a 
Table II. Role of SCD1 in metastatic cancers.

\begin{tabular}{|c|c|c|c|c|}
\hline Role & Type of cancer & System & Implicated mechanisms & Refs. \\
\hline $\begin{array}{l}\text { Fatty acid } \\
\text { desaturation }\end{array}$ & General & Patient & & $(83)$ \\
\hline \multirow{7}{*}{$\begin{array}{l}\text { Formation of } \\
\text { palmitoleate } \\
\text { and oleate }\end{array}$} & Breast cancers & Patients & & $(9,78-80,83-86)$ \\
\hline & & MCF-7 & ACC/AMPK & (19) \\
\hline & & MDA-MB-231 & GSK $3 \beta / \beta$-catenin & $(81)$ \\
\hline & & $\begin{array}{l}\text { MDA-MB-435, } \\
\text { MDA-MB-468, } \\
\text { SKBR3, BT-474 }\end{array}$ & & (11) \\
\hline & Lung cancer & SV40-WI38 & $\operatorname{PPAR} \gamma$ & (18) \\
\hline & & A549 & AMPK/ACC & (19) \\
\hline & & & AKT/GSK3 $\beta$ & (20) \\
\hline
\end{tabular}

positive correlation was observed between MUFA concentration and metastasis (85). Alteration of SFA/MUFA ratio in breast tumors does not reflect the dietary intake of patients but rather the change in fatty acid metabolism in cells (86) underlying a role for de novo synthesized MUFA and SCD1.

In lung adenocarcinomas, SCD1 knockdown inhibits AKT phosphorylation and activity (20) known to be associated with cancer progression (87). Silencing SCD1 in SV40-transformed lung fibroblasts and in breast cancer cells inhibits GSK3 $\beta$ phosphorylation (20).

Consequently, nuclear $\beta$-catenin translocation is decreased leading to lower expression of cyclin D1 and vimentin, two proteins associated with a mesenchymal phenotype (88). Silencing SCD1 in MCF7 and MDA-MB-231 breast cancer cells also increased E-cadherin expression associated with changes in cellular morphological aspects and decreased migration (81). It was also shown that palmitoleic acid (SCD1 product) is required to modify Wnt proteins leading to activation of the Wnt signaling pathway (89).

In breast cancer cells, we observed that the induction of $\beta$-catenin nuclear translocation by TGF $\beta$ is abrogated upon SCD1 silencing (Mounier et al, unpublished data). TGF $\beta$ acts as a tumor suppressor, but when cells become resistant to its action, it acts as a potent stimulator of malignant conversion (32). TGF- $\beta$ activates SCD1 expression through a Smad-dependent pathway (88). Constitutive activation of the EGF signaling pathways through the ErbB receptors has been associated with metastasis and poor prognostic for patients (91). Paradoxally, incubation of breast cancer cells with oleic acid inhibits the expression of HER2/neu suggesting an anti-metastatic effect of the product of SCD1 (92).

The role of SCD1 in EMT probably involves GSK3 $\beta$ activation and downstream cellular events modifying cell adhesion and migration. Certain evidence also point for a role of TGF $\beta$ and EGF in mediating SCD1 expression in metastasic cancer cells.

\section{Implication of other lipogenic genes}

General modification of the lipid profile during cancer progression is associated with increased expression of several genes involved in lipid metabolism (84). Apart from FAS and SCD1, the expression of other genes was modulated such as
ACC, INSIG1 (insulin-induced gene 1), SCAP (sterol regulatory element-binding protein cleavage-activating protein) and THRSP (thyroid hormone-responsive protein).

THRSP, also known as Spot14, is a nuclear protein that activates lipogenic genes (93). Low Spot14 expression was associated with prolonged survival in invasive breast cancers suggesting that Spot14 may not be a key player in EMT (93). Another study suggests that as breast cancer cells do not express lipoprotein lipase, lipids must be provided by a local environment such as breast lipids explaining why cancer cells with low Spot14 levels cannot survive in a low lipids concentration environment such as lymph nodes (94). The authors even suggest that elevated expression of Spot14 in cancer cells may provide a unique explanation for the elevated lipid synthesis in cancer cells.

Elevated ACC expression was also associated with a higher risk of infiltration in breast cancer (49). Amplification in ACC gene copy number was observed in breast cancer patients with reduced survival (95). Mutations in BCRA1, a gene associated with predisposition of inherited cancer, disrupt BCRA1 interaction with the inactive phosphorylated ACC. Consequently, ACC is dephosphorylated and activated (96). AMPK that phosphorylates ACC was also associated with malignancy providing energy for cancer cells (28). Adiponectin, an adipocytokine described as an anti-metastatic agent, inhibits ACC by increasing AMPK activity (97). In breast cancer cells, ACC is also regulated by a ubiquitin-dependent degradation process through its interaction with AKR1B10 (aldoketo reductase family 1 B10) (14). Pharmaceutical inhibition of ACC in cancer cells inhibits invadopodia formation, a membrane protrusion that facilitates matrix degradation and cellular invasion (98) but SCD1 is not required for invadopodia formation suggesting a different pathway. However, malonyl CoA decreases expression of the HER2/neu gene suggesting an anti-metastasic effect of ACC (99). This emphasizes the role of FAS in EMT as FAS decreases malonyl CoA content in cells.

Prostate cancer development and progression is often dependent of androgen and evidence indicates that androgen activation of the SREBP-dependent pathway may explain most of the androgen effects on lipogenesis (100). Androgen activates the cleavage of SREBP by increasing the 
expression of SCAP and INSIG (57). SREBP1 also increases reactive oxygen species (ROS) production (101) inducing tumor progression (102). A similar role of progesterone and EGF on SREBP cleavage and expression was reported in breast cancer cells $(22,65,67)$.

\section{Conclusions}

Increased lipogenesis is an important hallmark of cancer progression and metastasis. Part of this effect is probably mediated by SREBP1. However, evidence points to a role of lipogenic enzymes independent of SREBP1. ACC activity is regulated in cancer cells through phosphorylation by AMPK or by interaction with BCRA1. However, malonyl CoA, the product of ACC, has an anti-metastatic effect suggesting a more direct role of FAS on EMT. As such, a role for palmitate in the formation of membranes and rafts was suggested. Rafts allow recruitment and stabilization of receptors such as EGF, HER2/neu and MET increasing cancer progression. In contrast to FAS, SCD1 is not involved in the formation of invadopodia suggesting that if both enzymes are involved in EMT, they probably act through different mechanisms. Increased SCD1 activity decreases the level of SFA, the main ACC inhibitors activating lipogenesis in cancer cells. SCD1 is also probably directly involved in EMT. FAS and SCD1 may be the most interesting targets for the treatment of metastasic cancers, and pharmaceutical inhibitors already exist that could be used readily for the treatment of patients.

\section{References}

1. Medes G, Thomas A and Weinhouse S: Metabolism of neoplastic tissue. IV. A study of lipid synthesis in neoplastic tissue slices in vitro. Cancer Res 13: 27-29, 1953.

2. Swinnen JV, Brusselmans K and Verhoeven G: Increased lipogenesis in cancer cells: new players, novel targets. Curr Opin Clin Nutr Metab Care 9: 358-365, 2006.

3. Postic C and Girard J: The role of the lipogenic pathway in the development of hepatic steatosis. Diabetes Metab 34: 643-648, 2008.

4. Ntambi JM: The regulation of stearoyl-CoA desaturase (SCD). Prog Lipid Res 34: 139-150, 1995.

5. Neuschwander-Tetri BA: Hepatic lipotoxicity and the pathogenesis of nonalcoholic steatohepatitis: the central role of nontriglyceride fatty acid metabolites. Hepatology 52: 774-788, 2010.

6. Viollet B, Guigas B, Leclerc J, et al: AMP-activated protein kinase in the regulation of hepatic energy metabolism: from physiology to therapeutic perspectives. Acta Physiol (Oxf) 196: 81-98, 2009.

7. Viollet B, Foretz M, Guigas B, et al: Activation of AMP-activated protein kinase in the liver: a new strategy for the management of metabolic hepatic disorders. J Physiol 574: 41-53, 2006.

8. Kuhajda FP: Fatty-acid synthase and human cancer: new perspectives on its role in tumor biology. Nutrition 16: 202-208, 2000.

9. Bougnoux P, Chajes V, Lanson M, et al: Prognostic significance of tumor phosphatidylcholine stearic acid level in breast carcinoma. Breast Cancer Res Treat 20: 185-194, 1992.

10. Guo D, Reinitz F, Youssef M, et al: An LXR agonist promotes glioblastoma cell death through inhibition of an EGFR/AKT/SREBP-1/LDLR-dependent pathway. Cancer Discov 1: 442-456, 2011.

11. Nieva C, Marro M, Santana-Codina N, Rao S, Petrov D and Sierra A: The lipid phenotype of breast cancer cells characterized by Raman microspectroscopy: towards a stratification of malignancy. PLoS One 7: e46456, 2012.

12. Pizer ES, Chrest FJ, DiGiuseppe JA and Han WF: Pharmacological inhibitors of mammalian fatty acid synthase suppress DNA replication and induce apoptosis in tumor cell lines. Cancer Res 58: 4611-4615, 1998.
13. Horiguchi A, Asano T, Asano T, Ito K, Sumitomo M and Hayakawa M: Pharmacological inhibitor of fatty acid synthase suppresses growth and invasiveness of renal cancer cells. J Urol 180: 729-736, 2008.

14. Ma J, Yan R, Zu X, et al: Aldo-keto reductase family 1 B10 affects fatty acid synthesis by regulating the stability of acetyl-CoA carboxylase-alpha in breast cancer cells. J Biol Chem 283: 3418-3423, 2008 .

15. Chajes V, Cambot M, Moreau K, Lenoir GM and Joulin V: Acetyl-CoA carboxylase alpha is essential to breast cancer cell survival. Cancer Res 66: 5287-5294, 2006.

16. Brusselmans K, De Schrijver E, Verhoeven G and Swinnen JV: RNA interference-mediated silencing of the acetyl-CoAcarboxylase-alpha gene induces growth inhibition and apoptosis of prostate cancer cells. Cancer Res 65: 6719-6725, 2005.

17. Zhan Y, Ginanni N, Tota MR, et al: Control of cell growth and survival by enzymes of the fatty acid synthesis pathway in HCT-116 colon cancer cells. Clin Cancer Res 14: 5735-5742, 2008.

18. Scaglia N, Caviglia JM and Igal RA:High stearoyl-CoA desaturase protein and activity levels in simian virus 40 transformed-human lung fibroblasts. Biochim Biophys Acta 1687: 141-151, 2005.

19. Scaglia N, Chisholm JW and Igal RA: Inhibition of stearoylCoA desaturase-1 inactivates acetyl-CoA carboxylase and impairs proliferation in cancer cells: role of AMPK. PloS One 4: e6812, 2009.

20. Scaglia N and Igal RA: Inhibition of stearoyl-CoA desaturase 1 expression in human lung adenocarcinoma cells impairs tumorigenesis. Int J Oncol 33: 839-850, 2008.

21. Morgan-Lappe SE, Tucker LA, Huang X, et al: Identification of Ras-related nuclear protein, targeting protein for xenopus kinesin-like protein 2 , and stearoyl-CoA desaturase 1 as promising cancer targets from an RNAi-based screen. Cancer Res 67: 4390-4398, 2007.

22. Guo D, Prins RM, Dang J, et al: EGFR signaling through an Akt-SREBP-1-dependent, rapamycin-resistant pathway sensitizes glioblastomas to antilipogenic therapy. Sci Signal 2: ra82, 2009.

23. Zhang D, Tai LK, Wong LL, Chiu LL, Sethi SK and Koay ES: Proteomic study reveals that proteins involved in metabolic and detoxification pathways are highly expressed in HER-2/neupositive breast cancer. Mol Cell Proteomics 4: 1686-1696, 2005.

24. Porstmann T, Griffiths B, Chung YL, et al: PKB/Akt induces transcription of enzymes involved in cholesterol and fatty acid biosynthesis via activation of SREBP. Oncogene 24: 6465-6481, 2005.

25. Wang HQ, Altomare DA, Skele KL, et al: Positive feedback regulation between AKT activation and fatty acid synthase expression in ovarian carcinoma cells. Oncogene 24: 3574-3582, 2005.

26. Bandyopadhyay S, Pai SK, Watabe M, et al: FAS expression inversely correlates with PTEN level in prostate cancer and a PI 3-kinase inhibitor synergizes with FAS siRNA to induce apoptosis. Oncogene 24: 5389-5395, 2005.

27. Chang Y, Wang J, Lu X, Thewke DP and Mason RJ: KGF induces lipogenic genes through a PI3K and JNK/SREBP-1 pathway in H292 cells. J Lipid Res 46: 2624-2635, 2005.

28. Swinnen JV, Beckers A, Brusselmans K, et al: Mimicry of a cellular low energy status blocks tumor cell anabolism and suppresses the malignant phenotype. Cancer Res 65: 2441-2448, 2005.

29. Mehes G, Witt A, Kubista E and Ambros PF: Circulating breast cancer cells are frequently apoptotic. Am J Pathol 159: 17-20, 2001.

30. Iwatsuki M, Mimori K, Yokobori T, et al: Epithelialmesenchymal transition in cancer development and its clinical significance. Cancer Sci 101: 293-299, 2010.

31. Polyak K and Weinberg RA: Transitions between epithelial and mesenchymal states: acquisition of malignant and stem cell traits. Nat Rev Cancer 9: 265-273, 2009.

32. Thiery JP: Epithelial-mesenchymal transitions in tumour progression. Nat Rev Cancer 2: 442-454, 2002.

33. Voulgari A and Pintzas A: Epithelial-mesenchymal transition in cancer metastasis: mechanisms, markers and strategies to overcome drug resistance in the clinic. Biochim Biophys Acta 1796: 75-90, 2009

34. Yang J, Mani SA, Donaher JL, et al: Twist, a master regulator of morphogenesis, plays an essential role in tumor metastasis. Cell 117: 927-939, 2004.

35. Batlle E, Sancho E, Franci C, et al: The transcription factor snail is a repressor of E-cadherin gene expression in epithelial tumour cells. Nat Cell Biol 2: 84-89, 2000. 
36. Darnell JE Jr: Transcription factors as targets for cancer therapy. Nature reviews. Cancer 2: 740-749, 2002.

37. Moustakas A and Heldin $\mathrm{CH}$ : Signaling networks guiding epithelial-mesenchymal transitions during embryogenesis and cancer progression. Cancer Sci 98: 1512-1520, 2007.

38. Blobe GC, Schiemann WP and Lodish HF: Role of transforming growth factor beta in human disease. N Engl J Med 342: 1350-1358, 2000.

39. Stambolic V and Woodgett JR: Mitogen inactivation of glycogen synthase kinase-3 beta in intact cells via serine 9 phosphorylation. Biochem J 303: 701-704, 1994.

40. Peinado H, Portillo F and Cano A: Transcriptional regulation of cadherins during development and carcinogenesis. Int J Dev Biol 48: 365-375, 2004

41. Hamada F and Bienz M: The APC tumor suppressor binds to $\mathrm{C}$-terminal binding protein to divert nuclear beta-catenin from TCF. Dev Cell 7: 677-685, 2004.

42. He TC, Sparks AB, Rago C, et al: Identification of c-MYC as a target of the APC pathway. Science 281: 1509-1512, 1998.

43. Takeichi M, Nakagawa S, Aono S, Usui T and Uemura T: Patterning of cell assemblies regulated by adhesion receptors of the cadherin superfamily. Philos Trans R Soc Lond B Biol Sci 355: 885-890, 2000.

44. Efstathiou JA and Pignatelli M: Modulation of epithelial cell adhesion in gastrointestinal homeostasis. Am J Pathol 153 341-347, 1998

45. Wijnhoven BP and Pignatelli M: E-cadherin-catenin: more than a 'sticky' molecular complex. Lancet 354: 356-357, 1999.

46. Gilles C, Polette M, Mestdagt M, et al: Transactivation of vimentin by beta-catenin in human breast cancer cells. Cancer Res 63: 2658-2664, 2003

47. Takahashi M, Tsunoda T, Seiki M, Nakamura Y and Furukawa Y: Identification of membrane-type matrix metalloproteinase-1 as a target of the beta-catenin/Tcf4 complex in human colorectal cancers. Oncogene 21: 5861-5867, 2002.

48. Rakha EA: Pitfalls in outcome prediction of breast cancer. J Clin Pathol 66: 458-464, 2013

49. Milgraum LZ, Witters LA, Pasternack GR and Kuhajda FP: Enzymes of the fatty acid synthesis pathway are highly expressed in in situ breast carcinoma. Clin Cancer Res 3: 2115-2120, 1997

50. Epstein JI, Carmichael M and Partin AW: OA-519 (fatty acid synthase) as an independent predictor of pathologic state in adenocarcinoma of the prostate. Urology 45: 81-86, 1995.

51. Lupu R and Menendez JA: Targeting fatty acid synthase in breas and endometrial cancer: An alternative to selective estrogen receptor modulators? Endocrinology 147: 4056-4066, 2006.

52. Davidson B, Smith Y, Nesland JM, Kaern J, Reich R and Trope CG: Defining a prognostic marker panel for patients with ovarian serous carcinoma effusion. Hum Pathol 44: 2449-2460, 2013.

53. Pflug BR, Pecher SM, Brink AW, Nelson JB and Foster BA: Increased fatty acid synthase expression and activity during progression of prostate cancer in the TRAMP model. Prostate 57: 245-254, 2003

54. Greenberg NM, DeMayo F, Finegold MJ, et al: Prostate cancer in a transgenic mouse. Proc Natl Acad Sci USA 92: 3439-3443, 1995

55. Migita T, Ruiz S, Fornari A, Fiorentino M, Priolo C, Zadra G, et al: Fatty acid synthase: a metabolic enzyme and candidate oncogene in prostate cancer. J Natl Cancer Inst 101: 519-532, 2009.

56. Swinnen JV, Esquenet M, Goossens K, Heyns W and Verhoeven G: Androgens stimulate fatty acid synthase in the human prostate cancer cell line LNCaP. Cancer Res 57: 1086-1090, 1997.

57. Heemers H, Maes B, Foufelle F, Heyns W, Verhoeven G and Swinnen JV: Androgens stimulate lipogenic gene expression in prostate cancer cells by activation of the sterol regulatory element-binding protein cleavage activating protein/stero regulatory element-binding protein pathway. Mol Endocrino 15: 1817-1828, 2001

58. Van de Sande T, De Schrijver E, Heyns W, Verhoeven G and Swinnen JV: Role of the phosphatidylinositol 3'-kinase/PTEN/ Akt kinase pathway in the overexpression of fatty acid synthase in LNCaP prostate cancer cells. Cancer Res 62: 642-646, 2002.

59. Graner E, Tang D, Rossi S, et al: The isopeptidase USP2a regulates the stability of fatty acid synthase in prostate cancer Cancer Cell 5: 253-261, 2004.

60. Selvendiran K, Ahmed S, Dayton A, et al: HO-3867, a synthetic compound, inhibits the migration and invasion of ovarian carcinoma cells through downregulation of fatty acid synthase and focal adhesion kinase. Mol Cancer Res 8: 1188-1197, 2010.
61. Hsu YC and Liou YM: The anti-cancer effects of (-)-epigallocatechin-3-gallate on the signaling pathways associated with membrane receptors in MCF-7 cells. J Cell Physiol 226: 2721-2730, 2011

62. Menendez JA, Vellon L, Mehmi I, et al: Inhibition of fatty acid synthase (FAS) suppresses HER2/neu (erbB-2) oncogene overexpression in cancer cells. Proc Natl Acad Sci USA 101: 10715-10720, 2004.

63. Hartkopf AD, Banys M and Fehm T: HER2-positive DTCs/CTCs in breast cancer. Recent Results Cancer Res 195: 203-215, 2012.

64. Lee JS, Yoon IS, Lee MS, et al: Anticancer activity of pristimerin in epidermal growth factor receptor 2-positive SKBR3 human breast cancer cells. Biol Pharm Bull 36 316-325, 2013

65. Swinnen JV, Heemers H, Deboel L, Foufelle F, Heyns W and Verhoeven G: Stimulation of tumor-associated fatty acid synthase expression by growth factor activation of the sterol regulatory element-binding protein pathway. Oncogene 19 5173-5181, 2000

66. Oskouian B: Overexpression of fatty acid synthase in SKBR3 breast cancer cell line is mediated via a transcriptional mechanism. Cancer Lett 149: 43-51, 2000.

67. Kumar-Sinha C, Ignatoski KW, Lippman ME, Ethier SP and Chinnaiyan AM: Transcriptome analysis of HER2 reveals a molecular connection to fatty acid synthesis. Cancer Res 63: 132-139, 2003.

68. Nicolini A, Giardino R, Carpi A, et al: Metastatic breast cancer: an updating. Biomed Pharmacother 60: 548-556, 2006.

69. Camassei FD, Cozza R, Acquaviva A, et al: Expression of the lipogenic enzyme fatty acid synthase (FAS) in retinoblastoma and its correlation with tumor aggressiveness. Invest Ophthalmol Vis Sci 44: 2399-2403, 2003.

70. Rashid A, Pizer ES, Moga M, et al: Elevated expression of fatty acid synthase and fatty acid synthetic activity in colorectal neoplasia. Am J Pathol 150: 201-208, 1997.

71. Kalyankrishna S and Grandis JR: Epidermal growth factor receptor biology in head and neck cancer. J Clin Oncol 24: 2666-2672, 2006.

72. Qiu Z, Huang C, Sun J, et al: RNA interference-mediated signal transducers and activators of transcription 3 gene silencing inhibits invasion and metastasis of human pancreatic cancer cells. Cancer Sci 98: 1099-1106, 2007.

73. Horiguchi A, Asano T, Asano T, Ito K, Sumitomo M and Hayakawa M: Fatty acid synthase over expression is an indicator of tumor aggressiveness and poor prognosis in renal cell carcinoma. J Urol 180: 1137-1140, 2008.

74. Piyathilake CJ, Frost AR, Manne U, Bell WC, Weiss H, Heimburger DC, et al: The expression of fatty acid synthase (FASE) is an early event in the development and progression of squamous cell carcinoma of the lung. Hum Pathol 31: 1068-1073, 2000.

75. Carvalho MA, Zecchin KG, Seguin F, et al: Fatty acid synthase inhibition with Orlistat promotes apoptosis and reduces cell growth and lymph node metastasis in a mouse melanoma model. Int J Cancer 123: 2557-2565, 2008.

76. Murata S, Yanagisawa K, Fukunaga K, et al: Fatty acid synthase inhibitor cerulenin suppresses liver metastasis of colon cancer in mice. Cancer Sci 101: 1861-1865, 2010.

77. Zaytseva YY, Rychahou PG, Gulhati P, et al: Inhibition of fatty acid synthase attenuates CD44-associated signaling and reduces metastasis in colorectal cancer. Cancer Res 72: 1504-1517, 2012

78. Chajes V, Hulten K, Van Kappel AL, et al: Fatty-acid composition in serum phospholipids and risk of breast cancer: an incident case-control study in Sweden. Int J Cancer 83: 585-590, 1999.

79. Chajes V, Thiebaut AC, Rotival M, et al: Association between serum trans-monounsaturated fatty acids and breast cancer risk in the E3N-EPIC study. Am J Epidemiol 167: 1312-1320, 2008.

80. Pala V, Krogh V, Muti P, et al: Erythrocyte membrane fatty acids and subsequent breast cancer: a prospective Italian study. J Natl Cancer Inst 93: 1088-1095, 2001.

81. Mauvoisin D, Charfi C, Lounis AM, Rassart E and Mounier C: Decreasing stearoyl-CoA desaturase-1 expression inhibits betacatenin signaling in breast cancer cells. Cancer Sci 104: 36-42, 2013.

82. Goodridge AG: Regulation of the activity of acetyl coenzyme A carboxylase by palmitoyl coenzyme A and citrate. J Biol Chem 247: 6946-6952, 1972 
83. Zureik M, Ducimetiere P, Warnet JM and Orssaud G: Fatty acid proportions in cholesterol esters and risk of premature death from cancer in middle aged French men. BMJ 311: 1251-1254, 1995.

84. Petrek JA, Hudgins LC, Ho M, Bajorunas DR and Hirsch J: Fatty acid composition of adipose tissue, an indication of dietary fatty acids, and breast cancer prognosis. J Clin Oncol 15: 1377-1384, 1997.

85. Zhu ZR, Agren J, Mannisto S, et al: Fatty acid composition of breast adipose tissue in breast cancer patients and in patients with benign breast disease. Nutr Cancer 24: 151-160, 1995.

86. Simonsen NR, Fernandez-Crehuet Navajas J, Martin-Moreno JM, et al: Tissue stores of individual monounsaturated fatty acids and breast cancer: the EURAMIC study. European Community Multicenter Study on Antioxidants, Myocardial Infarction, and Breast Cancer. Am J Clin Nutr 68: 134-141, 1998.

87. Lamouille S and Derynck R: Emergence of the phosphoinositide 3-kinase-Akt-mammalian target of rapamycin axis in transforming growth factor-beta-induced epithelial-mesenchymal transition. Cells Tissues Organs 193: 8-22, 2011.

88. Lin SY, Xia W, Wang JC, et al: Beta-catenin, a novel prognostic marker for breast cancer: its roles in cyclin D1 expression and cancer progression. Proc Natl Acad Sci USA 97: 4262-4266, 2000.

89. Rios-Esteves J and Resh MD: Stearoyl CoA desaturase is required to produce active, lipid-modified Wnt proteins. Cell Rep 4: 1072-1081, 2013.

90. Samuel W, Nagineni CN, Kutty RK, et al: Transforming growth factor-beta regulates stearoyl coenzyme A desaturase expression through a Smad signaling pathway. J Biol Chem 277: 59-66, 2002.

91. McIntyre E, Blackburn E, Brown PJ, Johnson CG and Gullick WJ: The complete family of epidermal growth factor receptors and their ligands are co-ordinately expressed in breast cancer. Breast Cancer Res Treat 122: 105-110, 2010.

92. Menendez JA, Vazquez-Martin A, Ropero S, Colomer R and Lupu R: HER2 (erbB-2)-targeted effects of the omega-3 polyunsaturated fatty acid, alpha-linolenic acid (ALA; 18:3n-3), in breast cancer cells: the 'fat features' of the 'Mediterranean diet' as an 'anti-HER2 cocktail'. Clin Transl Oncol 8: 812-820, 2006.
93. Wells WA, Schwartz GN, Morganelli PM, Cole BF, Gibson JJ and Kinlaw WB: Expression of 'Spot 14' (THRSP) predicts disease free survival in invasive breast cancer: immunohistochemical analysis of a new molecular marker. Breast Cancer Res Treat 98: 231-240, 2006.

94.Kinlaw WB, Quinn JL, Wells WA, Roser-Jones C and Moncur JT: Spot 14: A marker of aggressive breast cancer and a potential therapeutic target. Endocrinology 147: 4048-4055, 2006

95. Chin K, DeVries S, Fridlyand J, et al: Genomic and transcriptional aberrations linked to breast cancer pathophysiologies. Cancer Cell 10: 529-541, 2006.

96. Moreau K, Dizin E, Ray H, et al: BRCA1 affects lipid synthesis through its interaction with acetyl-CoA carboxylase. J Biol Chem 281: 3172-3181, 2006.

97. Saxena NK and Sharma D: Metastasis suppression by adiponectin: LKB1 rises up to the challenge. Cell Adh Migr 4: 358-362, 2010.

98. Scott KE, Wheeler FB, Davis AL, Thomas MJ, Ntambi JM, Seals DF, et al: Metabolic regulation of invadopodia and invasion by acetyl-CoA carboxylase 1 and de novo lipogenesis. PloS One 7: e29761, 2012.

99. Menendez JA and Lupu R: Mediterranean dietary traditions for the molecular treatment of human cancer: anti-oncogenic actions of the main olive oil's monounsaturated fatty acid oleic acid (18:1n-9). Curr Pharm Biotechnol 7: 495-502, 2006.

100. Swinnen JV, Ulrix W, Heyns W and Verhoeven G: Coordinate regulation of lipogenic gene expression by androgens: evidence for a cascade mechanism involving sterol regulatory element binding proteins. Proc Natl Acad Sci USA 94: 12975-12980, 1997.

101. Huang WC, Li X, Liu J, Lin J and Chung LW: Activation of androgen receptor, lipogenesis, and oxidative stress converged by SREBP-1 is responsible for regulating growth and progression of prostate cancer cells. Mol Cancer Res 10: 133-142, 2012.

102. Bhandary B, Marahatta A, Kim HR and Chae HJ: Mitochondria in relation to cancer metastasis. J Bioenerg Biomembr 44: $623-627,2012$. 